\title{
A Review on Materials for Flame Retarding and Improving the Thermal Stability of Lithium Ion Batteries
}

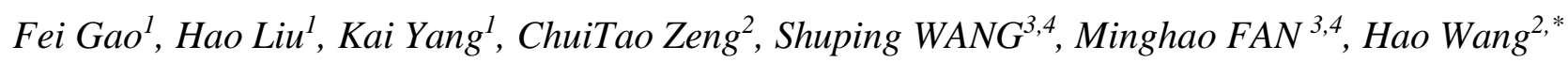 \\ ${ }^{1}$ State Key Laboratory of Operation and Control of Renewable Energy \& Storage Systems, China \\ Electric Power Research Institute, Beijing 100192, China \\ ${ }^{2}$ College of Materials Science \& Engineering, Beijing University of Technology, Beijing 100124, \\ China \\ ${ }^{3}$ Anhui Province Key Laboratory for Electric Fire and Safety Protection of State Grid Anhui Electric \\ Power Research Institute, Hefei 230022, China; \\ ${ }^{4}$ State Grid Laboratory of Fire Protection of Transmission and Distribution Facilities, Hefei 230022, \\ China \\ *E-mail: haowang@bjut.edu.cn
}

doi: $10.20964 / 2020.02 .24$

Received: 26 September 2019 / Accepted: 14 November 2019 / Published: 31 December 2019

Lithium-ion batteries (LIBs), featured by high energy density, high power density, excellent cycle performance and environmental friendliness, are widely used in electric equipment, electric vehicles and energy storage. However, accidents related to fires and explosions of LIBs occur frequently worldwide, some have caused serious threats to human life and health. The safety of LIBs is an extremely important and urgent research topic at present. This article aims to review recent key progresses in materials adopted for flame retarding and improving the thermal stability of LIBs from the external and internal parts, and inspire further improvement of various kinds of materials and strategies to improve LIBs safety, especially for emerging LIBs applications in large-scale energy storage fields.

Keywords: Lithium ion battery; Flame-retardant; Thermal stability

\section{FULL TEXT}

(C) 2020 The Authors. Published by ESG (www.electrochemsci.org). This article is an open access article distributed under the terms and conditions of the Creative Commons Attribution license (http://creativecommons.org/licenses/by/4.0/). 